\title{
Acute haematogenous septic arthritis of a lumbar facet joint in an otherwise healthy adolescent
}

\section{Artritis séptica hematógena aguda de una articulación facetaria lumbar en un adolescente sano}

https://doi.org/10.23938/ASSN.0644

\author{
S. García-Mata, Á. Hidalgo-Ovejero
}

\begin{abstract}
Facet joint septic arthritis is a rare cause of spinal infection in children with only four cases reported. The transmission pathway is believed to be haematogenous in $72 \%$ of cases.

The authors present the case of a 13-year-old boy hospitalised for acute lumbosciatalgia, limp and fever, with pain upon palpation of the paravertebral muscles, a positive Laségue signal and elevated serum inflammatory markers. The initial lumbar computerised tomography (TC) scan revealed no abnormalities in the interapophyseal joints. After improving on treatment with analgesics and antibiotics, he was readmitted one month later due to clinical deterioration, and septic arthritis of left facet joint L3-L4 was confirmed by magnetic resonance imaging (MRI). The patient experienced a full recovery after treatment with systemic antibiotics (cefotaxime-cloxacilin) and rehabilitation.

A high index of suspicion is necessary to diagnose this localization as a manifestation of lumbosciatalgia and/or limp in children. CT-scan or, preferably, MRI is mandatory to confirm this diagnosis.
\end{abstract}

Keywords. Septic arthritis. Facet joint. Spinal infection. Adolescent. Limp.

\section{RESUMEN}

La artritis séptica facetaria es una infección raquídea excepcional en niños, con solo cuatro casos publicados. Se cree que en el $72 \%$ de los casos el mecanismo de transmisión es hematógeno.

Se presenta el caso de un varón de 13 años que fue hospitalizado por lumbociatalgia aguda, cojera y fiebre, con contractura y dolor a la palpación de la musculatura paravertebral, signo de Laségue positivo y elevación de los marcadores séricos inflamatorios. La tomografía axial computarizada (TAC) inicial no mostró anomalías en las articulaciones interapofisarias lumbares. Tras haber mejorado con analgésicos y antibióticos, el paciente reingresó un mes más tarde por deterioro clínico de los síntomas, y la resonancia magnética (RMN) mostró artritis séptica de la articulación interfacetaria izquierda de L3-L4. El paciente obtuvo una recuperación completa con tratamiento antibiotico (cefotaximacloxacilina) y rehabilitación.

Se requiere un alto grado de sospecha para poder diagnosticar esta localización anatómica como manifestación de lumbociática y/o cojera en niños. Se requiere TAC o, preferiblemente, RMN para confirmar el diagnóstico.

Palabras clave. Artitis séptica. Articulación interapofisaria. Infección raquis. Adolescente. Cojera.
Pediatric Trauma and Orthopaedic Section. Surgery and Traumatology Department. Complejo Hospitalario de Navarra. Pamplona.

Recepción: 17/01/2019

Aceptación provisional: 20/05/2019

Aceptación definitiva: 10/06/2019

\section{Correspondencia:}

Serafin García Mata

Servicio de Cirugía Ortopédica y Traumatología

Complejo Hospitalario de Navarra

$\mathrm{C} /$ Irunlarrea, 3

31008 Pamplona

E-mail: sgmata@telefonica.net 


\section{INTRODUCTION}

Spinal infections are a rare cause of low back pain that can be distinguished depending on the specific compartment that they affect: vertebral body (osteomyelitis), intervertebral disc (discitis), epidural space or paravertebral region (abscesses) ${ }^{1}$. Cases of facet joint septic arthritis, which accounts for $4 \%$ of spinal infections with an incidence of $0.2-2 / 10,000$ of overall hospital $\operatorname{admissions}^{2,3}$, have on rare occasions been reported as the cause of low back pain. To the authors' knowledge, only four cases in children of facet joint septic arthritis, of probable haematogenous origin, have been previously published ${ }^{4-7}$.

Our aim is to present a new case in an otherwise healthy 13-year-old boy with an episode of acute lumbosciatalgia, limp and fever, initially treated in accordance with a low back and radicular pain standard management protocol without a noticeable improvement in his clinical condition. This case highlights the fact that a high degree of suspicion is required in the differential diagnosis of spinal infection to consider the possibility of facet joint infection. We also emphasize the complementary imaging study required to perform a correct differential diagnosis.

\section{CASO CLÍNICO}

A 13-year-old male patient admitted to a community hospital following two days of left lumbosciatalgia, lower lumbar back pain and limp which started after physical exertion, together with fever $\left(38^{\circ} \mathrm{C}\right)$ in the previous 24 hours.

The physical examination revealed limp and a severe bilateral lumbar paravertebral muscle spasm predominantly on the left side, with pain upon application of pressure on the sciatic nerve and a left Straight Leg Raise Test positive (+) at $30^{\circ}$. He had no neurological deficit in the lower limbs, and no septic site was found that could clinically explain the concurrent fever $\left(39.5^{\circ} \mathrm{C}\right)$. There was no change to the overlying skin's appearance. Lumbar hyperextension performed in double stance was scarce and painful. Gatrointestinal, pulmonary, upper and lower airways and genitourinary infections were ruled out by the Pediatricians. The Rheumatology Depart- ment ruled out spondyloarthropathy and associated rheumatic diseases. The acute phase reactants of inflammation were elevated with an ESR (Eritrocite Sedimentation Rate) of $73 \mathrm{~mm}$ and CRP (C-Reactive Protein) of $11 \mathrm{mg} / \mathrm{l}$. The blood culture, serology for brucellosis and antigen HLA-B27 blood test (to rule out inflammatory diseases of the spine) were all negative. A simple lumbosacral spine X-ray revealed no abnormalities, while the CT scan showed a slight narrowing of the L5-S1 disc space, disc protrusion at L3-L4 and L4-L5 and lumbosacral transitional anomalies with no other abnormalities. He was treated by paediatrician with NSAIDs (Nonsteroidal anti-inflammatory drugs), corticosteroids, benzodiazepines and cefuroxime (for 8 days), with improved low back pain, abatement of fever and normalized blood count, CRP and ESR. Following a positive Mantoux test and incomplete isoniazid treatment two years before, it was decided to reintroduce anti-tuberculosis chemoprophylaxis.

Three weeks later he was referred to opinion of our Pediatric Orthopaedic Service following a presumptive diagnosis of discitis. The patient reported low-intensity low back pain without fever, paravertebral muscle spasm upon fist percussion of the L2-S1 spinous processes and left irritated sciatic nerve symptoms. The Ga-67/ Tc-99 scintigraphy revealed pathological hyperfixation of the radiotracer in the left L3-L4 hemivertebral region (Fig. 1). A lumbosacral magnetic resonance imaging scan (MRI) with gadolinium was ordered, which revealed a small amount of intra-articular fluid at the left L3-L4 interapophyseal joint (Fig. 2) due to facet joint abscess. Under the diagnosis of left L3-L4 lumbar interapophyseal septic arthritis, treatment was initiated with cefotaxime and cloxacillin (intravenous) for eight days. Given the patient's rapid clinical improvement, he was discharged with cloxacillin (oral) on an outpatient basis for a further three weeks. He continued to improve with complete resolution of symptoms.

The gadolinium MRI conducted one month later showed a significant reduction in fluid in the L3-L4 interapophyseal joint (Fig. 3) and the CT scan revealed sclerosis of the plates and interapophyseal joints at L3 with rarefaction of the L3-L4 left articular surface and some subchondral cystic lesions (Fig. 4), on the contrary to the initial CT scan.

After intermittent rehabilitation spanning fifteen months, low back pain abated and the patient could resume normal life. The rehabilitation treatment was carried out due to the slight and intermittent paravertebral contracture. Four and a half years later, the patient continued to be asymptomatic. 


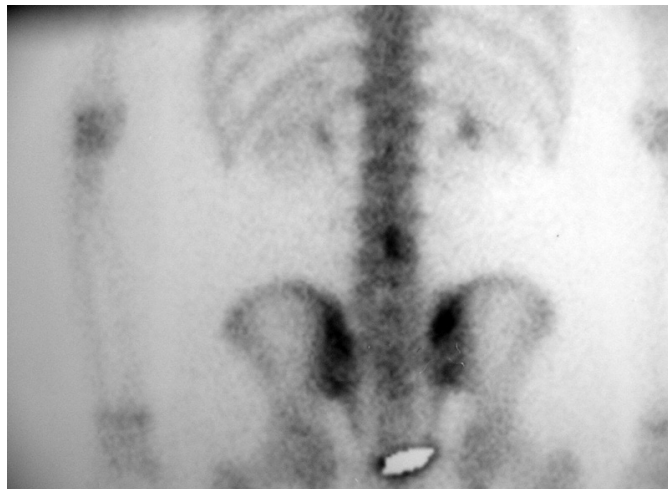

Figure 1. Ga-67/Tc-99 scintigraphy revealing pathological hyperfixation of the radiotracer in the left L3-L4 hemivertebral region.
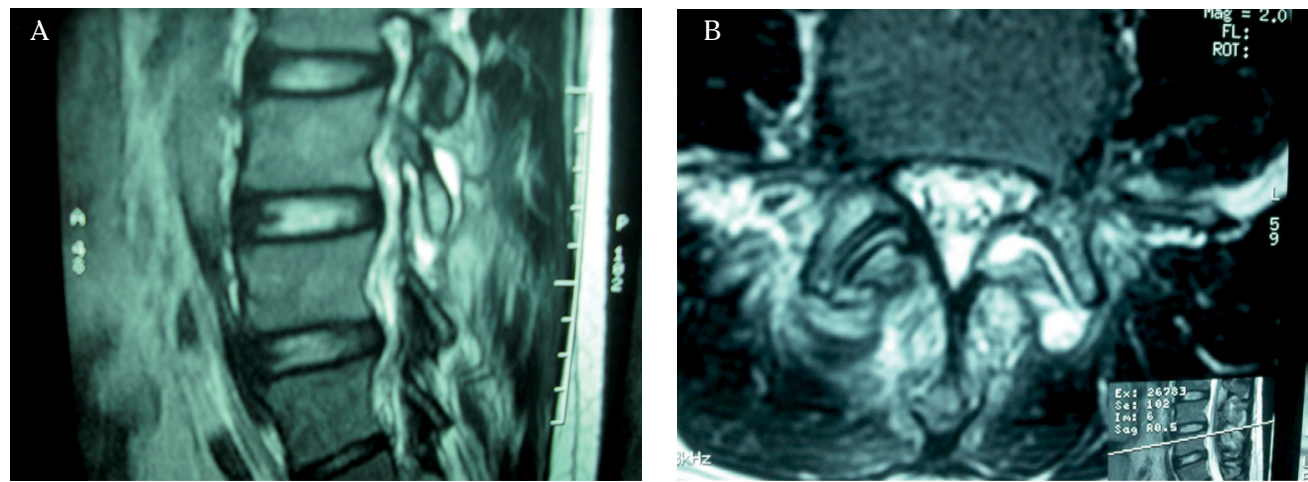

Figure 2. MRI revealing a small amount of intra-articular fluid at the left L3-L4 interapophyseal joint in sagital T2-weighted (A) and axial T2-weighted (B) images showing hyperintensity signal due to the facet joint abscess.
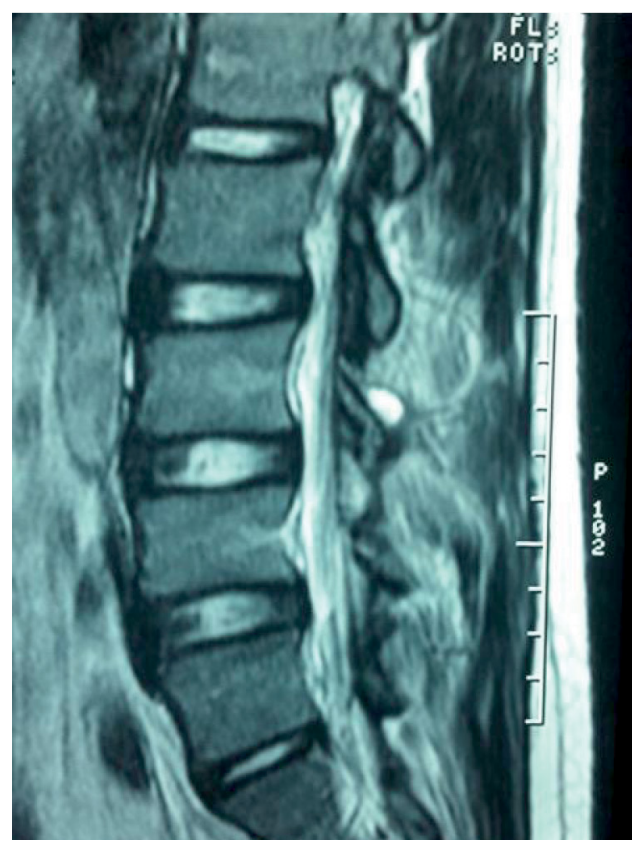

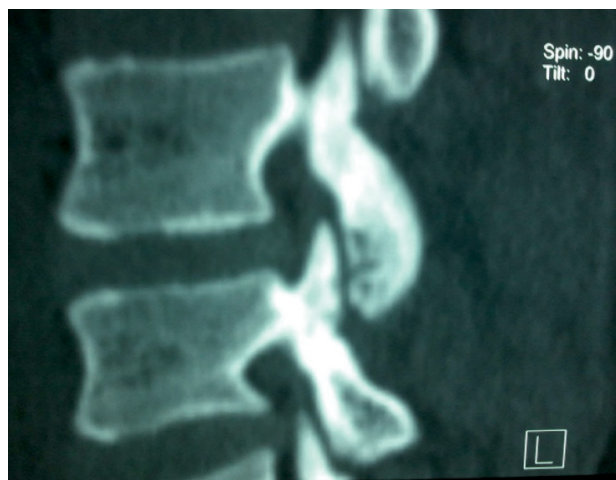

Figure 4. Sagital CT-scan revealing sclerosis of the interapophyseal joints at L3 with rarefaction of the L3-L4 left articular surface and some subchondral cystic lesions.

Figure 3. Sagital T2-weighted image of MRI one month later showed a significant reduction in fluid in the left L3-L4 interapophyseal joint. 


\section{DISCUSSION}

Most of cases of facet joint septic arthritis are believed to be haematogenous $(72 \%)^{8}$, being epidural injection, acupuncture, joint surgery, penetrating wounds and the spread of adjacent sites of infection other reported sources of infection ${ }^{3,9}$.

Since 1987, only four cases of haematogenous interapophyseal infectious arthritis in paediatric patients have been published in the medical literature, three in lumbar spine: 18 month-old (right L4-L5), 8 year-old (left L5-S1), 10 year-old (left L4-L5) ${ }^{4-6}$ and one in thoracic spine: 8 year-old (left T11$12)^{7}$. The first patient presented with a septic pharyngeal infection and the third one with a positive urine culture, while no primary infection was present in the second patient. The origin of primary infection in the fourth patient, as well as their number of symptomatic days, were not reported.

Immunosuppression, intravenous drug addiction, diabetes mellitus, liver cirrhosis, kidney failure, neoplastic diseases and other chronic conditions have been reported as predisposing factors to haematogenous facet joint arthritis ${ }^{8}$. None of the paediatric cases published, including ours, found associated immunosuppressive factors.

The most-commonly isolated aetiological agent in adults is Staphylococcus aureus $^{2}$; Escherichia coli was reported following urinary tract infection ${ }^{2}$, and methicillin resistant Staphylococus aureus was rarely reported ${ }^{10,11}$. The infection-inducing microorganism could not be isolated in two of the children while, from the other two, Staphylococcus epidermidis and Enterococcus faecalis were cultured from samples obtained from blood and urine cultures, respective$\mathrm{ly}^{5,6}$.

A thorough both medical history and physical examination are essential in order to correctly diagnose patients with facet joint septic arthritis ${ }^{9}$. The patient reported regular acute pain of the affected vertebral segment accompanied by fever, pain upon palpation of the paravertebral muscles and spasm. Average symptom duration in the three cases prior to diagnosis was 5.3 days, and pain was not sciatic nor did it extend to the buttock or thigh. One of these cases presented with leg weakness, one episode of urinary incontinence and antalgic gait with plantar flexion ${ }^{6}$. The main symptom of the 18-month-old patient was limping ${ }^{4}$. Therefore, this diagnose has also to be included in the differential diagnose of limping in children.

The diagnostic process should include a differential white blood cell count, ESR, CRP and blood cultures ${ }^{8}$. All paediatric patients presented with high ESR levels.

Plain X-ray does not contribute with useful information to the initial diagnostic process of this condition, although some authors report expansion of the facet joint space or non-specific lytic or sclerotic changes in a sub-acute or chronic setting; this situation can be observed in the CTscan after the recovery (Fig. 4). It may also go unnoticed in the CT scan, while scintigraphy is a sensitive but non-specific test; MRI was the confirmatory diagnostic test of facet joint septic arthritis in all paediatric cases reported. It is the most sensitive and specific of all the imaging tests used to diagnose this condition and the administration of gadolinium contrast medium reveals inflammatory and/or infectious changes and the formation of abscesses ${ }^{9}$. Interapophyseal punction for bacterial culture was not performed due to the fact that antibiotics were previously given by paediatrician and for the good response to cefotaxime and cloxacillin.

Two children presented with an extradural mass from the lower thoracic area to the sacrum with maximum L4-L5 thecal compression $^{6}$ and in T11-12 ${ }^{7}$ for epidural abscess. Other adult patients reported complications are meningoencephalitis without fever or risk factors ${ }^{12}$, paraspinal abscess $^{13}$, progressive quadriplegia ${ }^{14}$ and generalized infection ${ }^{15}$. Our patient's condition took more than one month to be diagnosed, as reported for adults ${ }^{9,16}$, and the working diagnosis was infectious discitis or acute vertebral osteomyelitis until the interapophyseal source of the infection was identified.

The administration of systemic antibiotics, conservative theraphy, was curative in 
all four paediatric patients, and all recovered normal functionality without sequelae.

At the end of the process, physical treatment was carried out in our patient in order to eliminate the slight and intermittent residual paravertebral contracture.

The conclusion to be drawn from this process is that a high degree of suspicion is needed for early diagnosis of facet joint infection in patients presenting with spinal infection (acute low back pain, fever and/ or intense pain upon palpation of the paravertebral muscles, with or without a limp, together with increased levels of acute phase reactants of inflammation). Unilateral involvement and symptom progression in fewer than four weeks helps to differentiate it from infectious spondylodiscitis ${ }^{3}$; blood cultures are required but a gadolinium MRI must be carried out to confirm the diagnosis.

\section{BIBLIOGRAFÍA}

1. Boos N. Infections of the spine. En: Boos N, Aebi M, editores. Spinal Disorders. Fundamentals of diagnosis and treatment. Berlin: Springer-Verlag, 2008: 1021-1037. https://doi. org/10.1007/978-3-540-69091-7

2. Herrero Herrero Ji, García Aparicio J. Escherichia coli septic arthritis of a lumbar facet joint following urinary tract infection. Int J Infect Dis 2011; 15: e63-5. https://doi. org/10.1016/j.ijid.2009.11.004

3. HARRIEs LW, WatURA R. Septic arthritis of unilateral lumbar facet joint with contiguous abscess, without prior intervention. BMJ Case Rep 2012; 2: 1-8. https://doi.org/10.1136/ bcr.09.2011.4849

4. Mas-Atance J, Gil-García Mi, Jover-Sáenz A, Curià-Jové E, Jové-Talavera R, Charlez-Marco A et al. Septic of a posterior lumbar facet joint in an infant. Spine (Phila Pa 1976) 2009; 34: E465-468. https://doi.org/10.1097/ BRS.0b013e3181a4e64b

5. Smida M, LejRi M, Kandara H, Sayed M, Ben Chehida F, Ben Ghachem M. Septic arthritis of a lumbar facet joint case report and review of the literature. Acta Orthop Belg 2004. 70: 290-294.
6. Heenan SD, Brton J. Septic arthritis in a lumbar facet joint: a rare cause of an epidural abscess. Neuroradiology 1995; 37: 462-464. https://doi.org/10.1007/BF00600094

7. French R, Purushothaman B, Roysam GS, LaKshMANAN P. Pediatric facet joint septic arthritis. Spine J 2015; 15: 1686-1688. https://doi. org/10.1016/j.spinee.2015.02.006

8. Stecher JM, El-Khoury GY, Hitchon PW. Cervical facet joint septic arthritis: a case report. Iowa Orthop J 2010; 30: 182-187.

9. Klekot D, Zimny A, CZapiga B, SĄSIAdeK M. Isolated septic facet joint arthritis as a rare cause of acute and chronic low back pain - a case report and literature review. Pol J Radiol 2012; 77: 72-76. https://doi.org/10.12659/ PJR.883634

10. Krishnan V, Amritanand R, Sundararaj GD. Methicillin-resistant Staphylococcus aureus as a cause of lumbar facet joint septic arthritis: a report of two cases. J Bone Joint Surg Am 2010; 92: 465-468. https://doi.org/10.2106/JBJS.H.01888

11. Papaliodis DN, Roberts TT, Richardson NG, LaWRENCE JB. Spontaneous septic arthritis of the lumbar facet caused by methicillin-resistant Staphylococcus aureus in an otherwise healthy adolescent. Am J Orthop (Belle Mead NJ) 2014; 43: 325-327.

12. Simon EL, Gair L, Kovacs M. Meningoencephalitis caused by septic arthritis of a lumbar facet joint in a patient without fever or risks factors. Am J Emerg Med 2016; 34: 762.e1-2. https://doi.org/10.1016/j.ajem.2015.08.028

13. Kitova-John MB, Azim-Araghi A, Sheikh FT, KITOV BD. Idiopathic septic arthritis of a lumbar facet joint associated with paraspinal abscess. BMJ Case Rep 2015. https://doi. org/10.1136/bcr-2015-211135

14. Raeymaeckers S, Nieboer K, De Mey J. Progressive quadriplejia resulting from septic facet joint arthritis. JBR-BTR 2015; 98: 58. https:// doi.org/10.5334/jbr-btr.764

15. Kim SY, Han SH, Jung MW, Hong JH. Generalized infection following facet joint injection -A case report-. Korean J Anesthesiol 2010; 58: 401-404. https://doi.org/10.4097/ kjae.2010.58.4.401

16. HalPin DS, GiBSON RD. Septic arthritis of a lumbar facet joint. J Bone Joint Surg 1987; 69-B: 457-459. https://doi.org/10.1302/0301620X.69B3.3584201 
